\title{
DIREITOS E ERROS NA DEMARCAÇÃO DE TERRAS INDÍGENAS ${ }^{1}$ DERECHOS Y ERRORES EN LA DEMARCACIÓN DE LAS TIERRAS INDÍGENAS
}

\section{RIGHTS AND MISTAKES IN THE DEMARCATION OF INDIGENOUS LANDS}

Gladstone Avelino Britto

\begin{abstract}
RESUMO: O processo de demarcação de terras indígenas tem fundamento na Constituição de 1988, cabendo à Fundação Nacional do Índio (Funai) a realização dos trabalhos, dentro de sua competência de dar cumprimento à política indigenista no Brasil. Este artigo busca decifrar os mecanismos internos que regem a demarcação dessas terras e avaliar a importância da qualidade técnica do Relatório Circunstanciado de Delimitação e Identificação (RCID), principal componente de um processo administrativo conduzido por um antropólogo de qualificação reconhecida. A boa técnica na elaboração do RCID contribui para agilizar o processo de reconhecimento dos direitos dos povos indígenas à terra. Examinaram-se os procedimentos administrativos do Decreto no 1775/1996 e da Portaria MJ no 14/1996 e sua aplicação em processos de elaboração do RCID. A não observância de critérios legais na elaboração do RCID e o cerceamento ao direito constitucional ao contraditório no processo administrativo estão na raiz da insegurança jurídica nos processos de reconhecimento dos direitos indígenas sobre as terras que esses tradicionalmente ocupam.
\end{abstract}

Palavras-chave: territórios, insegurança jurídica, direitos originários, Funai, RCID.

RESUMEN: El proceso de demarcación de tierras indígenas tiene fundamento en la Constitución de 1988, habiendo realizado la Fundação Nacional do Índio (Funai) los trabajos de su competencia de dar cumplimiento con la política indígena en Brasil. Este artículo se propone descifrar los mecanismos internos que rigen la demarcación de las tierras y evaluar la importancia de la calidad técnica robusta, esto según el informe de alcance e identificación (RCID) principal componente de un proceso administrativo conducido por un antropólogo de calidad reconocida. Una buena técnica en la preparación del RCID contribuye a agilizar el proceso de reconocimiento de los derechos de los pueblos indígenas en la tierra. Se examinaran los procedimientos administrativos del decreto $\mathrm{N}^{\circ} 1775 / 1996 \mathrm{y}$ la Ordenanza del Ministerio de Justicia No 14/1996 y su aplicación en la preparación de los procesos RCID. La no observación de criterios legales en la elaboración de RCID y la restricción al derecho constitucional a las contradicciones en el proceso administrativo están a raíz de la inseguridad

\footnotetext{
${ }^{1}$ Mestrado em Economia. Programa de Pós-Graduação em Agronegócios. Faculdade de Economia da Universidade Federal de Mato Grosso. Financiamento: UFMT.

2 Mestre em Direito Agroambiental e mestrando em Agronegócios e Desenvolvimento Regional/UFMT. Endereço eletrônico: gladstone.britto@gmail.com.
} 
jurídica en los procesos de reconocimiento de los derechos indígenas en las tierras que tradicionalmente ocupan.

Palabras clave: territórios, inseguridad jurídica, derechos originales, Funai, RCID.

ABSTRACT: The indigenous land demarcation process in Brazil was better established by the promulgation of Brazilian Constitution of 1988, being mandatory to Fundação Nacional do Índio (Funai) to carry out the related works within its competence to comply with the indigenous policy in Brazil. This article intends to comprehend the mechanisms behind such land demarcation, as well as to assess the importance of the technical quality of the Robust Scoping Report and Identification (RCID), which is the main component of an administrative procedure conducted by a recognized qualified anthropologist. Good methodology in preparing the RCID contributes to expedite the process of recognition of the rights of indigenous peoples to land. It was examined whether the administrative procedures of Decree No. 1775/1996 and MJ Ordinance No. 14/1996 were applied in the RCID elaboration processes. Failure to comply with legal criteria in preparing the RCID and the restriction of the constitutional right to adversarial in the administrative process are at the root of the legal uncertainty in the processes of recognition of indigenous rights to lands they traditionally occupy.

Keywords: territories, legal uncertainty, original rights, Funai, RCID.

\section{Introdução}

A demarcação de terras indígenas (TIs) decorre de procedimento administrativo conduzido pela Fundação Nacional do Índio (Funai), que reconhece direitos originários e os faz prevalecer sobre quaisquer atos que tenham por objeto o domínio e a posse pelos não índios sobre as áreas tradicionalmente ocupadas pelas etnias indígenas. Os estudos caracterizadores dessa ocupação devem descrever os usos, os costumes e tradições do povo indígena que reivindica a terra. O Grupo Técnico (GT) nomeado pela Funai elabora um Relatório Circunstanciado de Identificação e Delimitação (RCID), que deve conter dados etnográficos, históricos, sociológicos, populacionais, ambientais e fundiários do povo indígena. $O$ trabalho que servirá de base para a decisão da Administração quanto à demarcação da área deve ser suficientemente claro, conferindo coerência com os levantamentos antropológicos, sociais ou ambientais descritos. 
Imprecisões técnicas no relatório acarretam prejuízos aos direitos dos índios ou das partes afetadas. Juízos subjetivos por parte do GT da Funai, na definição dos limites propostos para as áreas a serem demarcadas, podem agravar o ambiente de insegurança jurídica.

\section{Fundamentos da demarcação das Terras Indígenas}

A Constituição da República Federativa do Brasil, promulgada em 05 de outubro de 1988, apresentou, de forma inovadora, um capítulo próprio contendo os fundamentos jurídicos no que concerne à garantia dos direitos dos índios sobre as terras que tradicionalmente ocupam. O artigo 231 da Constituição informa quanto à natureza originária desses direitos, cuja ideia subjacente é a de que o reconhecimento sobre as terras que os índios tradicionalmente ocupam prevalece sobre quaisquer outras formas de aquisição de domínio. Na falta de Lei específica, a Constituição é regulada pelo Decreto 1775/1996, com complemento normativo dado pela Portaria do Ministério da Justiça 14/1996. Essas normas estabelecem um rito no processo administrativo para fins de identificação e delimitação das áreas envolvidas e possível demarcação parcial ou total das áreas reivindicadas pelos povos indígenas afetados.

1.1 Direitos constitucionais e limites para o reconhecimento

Com uma série de inovações no tratamento da questão indígena, indicando novos parâmetros para a relação do Estado e da sociedade brasileira para com os índios, a Constituição de 1988 trouxe um avanço significativo na proteção e no reconhecimento dos direitos dos povos indígenas no país, fazendo dela uma espécie de marco divisor para a avaliação da situação dos índios no Brasil nos dias de hoje (ARAÚJO, 2004).

Uma linha argumentativa procura estabelecer uma vinculação entre 0 direito dos índios à terra que habitam e seus direitos fundamentais, 
enquanto indivíduos. Ellen Romero explora essa ideia ao afirmar que a leitura possível para a Constituição é que, para que se possa ter uma garantia do "mínimo existencial ecológico", que permita assegurar a dignidade e a qualidade de vida dos povos indígenas, é necessário associar os direitos decorrentes do artigo 231 aos direitos fundamentais previstos no artigo 50, parágrafo 20, da Constituição, por serem esses "garantia fundamental às condições materiais que asseguram uma vida com dignidade" (ROMERO, 2012, p. 97).

O reconhecimento dos direitos dos índios sobre as terras que tradicionalmente habitam não foi inovação da Constituição de 1988. A partir da Constituição de 1934, todas as seis constituições então vigentes ${ }^{3}$, incluindo as cartas impostas por duas ditaduras distintas, em 1937 e em 1969, garantiram o acesso dos "silvícolas"4 à terra.

Ao estabelecer que o ato de demarcação tem natureza jurídica de direitos originários, a Constituição descaracterizou aqueles direitos preexistentes em relação a domínio e posse de terras indígenas pelos não índios, remetendo o direito às terras tradicionalmente ocupadas pelos índios a uma situação jurídica preexistente. O direito dos índios às terras que ocupam é imemorial, pré-existente em relação aos demais direitos constituídos a partir da colonização do Brasil. Assim, o processo

\footnotetext{
${ }^{3} \mathrm{Na}$ CF 1934: "Art. 129 - Será respeitada a posse de terras de silvícolas que nelas se achem permanentemente localizados, sendo-Ihes, no entanto, vedado aliená-las; na CF 1937: Art. 154 - Será respeitada aos silvícolas a posse das terras em que se achem localizados em caráter permanente, sendo-Ihes, porém, vedada a alienação das mesmas; na CF 1946: Art. 216 - Será respeitada aos silvícolas a posse das terras onde se achem permanentemente localizados, com a condição de não a transferirem; na CF 1967: Art. 186 - É assegurada aos silvícolas a posse permanente das terras que habitam e reconhecido o seu direito ao usufruto exclusivo dos recursos naturais e de todas as utilidades nelas existentes; na CF 1967, com a redação dada pela Emenda Constitucional no 1, de 17/10/1969: Art. 198. As terras habitadas pelos silvícolas são inalienáveis nos termos que a lei federal determinar, a eles cabendo a sua posse permanente e ficando reconhecido o seu direito ao usufruto exclusivo das riquezas naturais e de todas as utilidades nelas existentes. $\S 1^{\circ}$ Ficam declaradas a nulidade e a extinção dos efeitos jurídicos de qualquer natureza que tenham por objeto o domínio, a posse ou a ocupação de terras habitadas pelos silvícolas. $\S 20 \mathrm{~A}$ nulidade e extinção de que trata o parágrafo anterior não dão aos ocupantes direito a qualquer ação ou indenização contra a União e a Fundação Nacional do Índio."

4 Palavra em desuso nos textos legais atuais, foi a forma pela qual as revogadas constituições se referiam aos povos indígenas. "Silvícola" provém, etimologicamente, de expressão que designa quem nasce ou vive nas selvas. Índios nem sempre habitam em áreas rurais (os expulsos da terra, por exemplo). Silvícola também é sinônimo de selvagem. Este último significado contém carga psicológica negativa. Selvagens são a designação comum de espécies animais que podem reagir de forma imprevisível, por não respeitar regras de conduta humana, circunstância que não se aplica aos índios.
} 
administrativo busca traduzir um direito mais antigo do que qualquer outro. Nesse sentido, a decisão administrativa que demarca os territórios indígenas tem força jurídica para preponderar sobre direitos materializados em escrituras públicas ou títulos de legitimação de posse, os quais foram declarados como "nulos e extintos", conforme o parágrafo $6^{\circ}$ do artigo 231.

O prazo em que se dará tal reconhecimento foi estabelecido no artigo 67 do Ato das Disposições Constitucionais Transitórias da Constituição, que proclama o limite temporal de cinco anos para a demarcação dos territórios indígenas.

Para Paulo de Bessa Antunes "tanto a norma legal" quanto a constitucional restaram letras mortas" (ANTUNES, 2012, p. 1108). Contudo, em decisão do Supremo Tribunal Federal (STF), foi afastado qualquer entendimento pela invalidade da continuidade dos processos demarcatórios assinalando que "o prazo previsto no art. 67 do Ato das Disposições Constitucionais Transitórias não é peremptório. Sinalizou simplesmente visão prognóstica sobre o término dos trabalhos de demarcação e, portanto, a realização destes em tempo razoável" (BRASIL, PODER JUDICIÁRIO FEDERAL, SUPERIOR TRIBUNAL FEDERAL, 2004, p. 7).

A demarcação das terras tradicionalmente ocupadas pelos índios requer que as etnias respectivas continuem habitando tais terras em caráter permanente, conforme foi o desejo do constituinte originário de 1988, e isso exige a realização de um trabalho técnico de natureza antropológica visando descrever as quatro situações cumulativas previstas no artigo 231 da Constituição ${ }^{6}$.

\footnotetext{
${ }^{5}$ Havia um dispositivo semelhante no Estatuto do Índio (Lei 6.001/1973, art. 65).

${ }^{6}$ Conf. Constituição, Art. 231, § 10, são terras tradicionalmente ocupadas pelos índios: 1) as por eles habitadas em caráter permanente; 2) as utilizadas em atividades produtivas; 3 ) as imprescindíveis à preservação dos recursos ambientais necessários ao bem-estar dos povos indígenas; 4) as necessárias à reprodução física e cultural dos índios, segundo seus usos, costumes e tradições.
} 
1.2 Tradicionalidade da ocupação, territorialidade e imemoriabilidade

Para os povos indígenas, o espaço ou território reivindicado deve ser importante no sentido de preservar o sentido da territorialidade associado à identidade própria do grupo étnico e ao respeito às crenças, usos, costumes, línguas, tradições e especificidades de cada povo indígena. Ou seja, o que se reivindica é uma terra que tenha relação direta com o território reivindicado por esses povos. Cabe destacar a diferença entre terra e território. Conforme Sauer (2011, p. 419), ainda que no artigo 13 da Convenção da Organização Internacional do Trabalho (OIT) no 169 se tomem tais conceitos como sinônimos, a utilização do termo "terras" nos artigos 15 e 16 da Convenção deveria incluir o conceito de territórios, o que abrange a totalidade do habitat das regiões que os povos interessados ocupam ou utilizam de alguma outra forma.

O Estatuto da Terra, Lei no 4.504/1964, contém acepção diferente da Convenção da OIT, uma vez que considera terra apenas um meio de produção. Em outros termos, terra nada mais seria do que um bem constituído pelo solo e por tudo quanto se lhe incorporar natural ou artificialmente. Ao conceituar o território como a área necessária à reprodução cultural, social e econômica dos povos, cria-se um elemento de identificação inexistente na noção de terra. Portanto, é necessária a vinculação de terra ao espaço necessário para que grupos culturalmente diferenciados se reconheçam como tais e assumam formas próprias de organização social, destinando os recursos naturais presentes na terra para sua reprodução cultural, social, religiosa, ancestral e econômica, utilizando conhecimentos, inovações e práticas gerados e transmitidos pela tradição.

Portanto, o território é valorado segundo critérios diferentes da terra. Carlos Teodoro Irigaray também considera o conceito corrente de terra insuficiente para designar o habitat. Uma particularidade do território indígena seria o sentido do coletivo e de pertencimento para o grupo. É por isso que não existem espaços privativos de determinados indivíduos dentre os índios, de vez que todos têm acesso ao território (IRIGARAY, 2007, p. 88). 
O fazer da etnografia, que exige uma negociação construtiva envolvendo sujeitos conscientes e politicamente significativos, pode agregar elementos que possibilitam a compreensão desse modo característico de pensar que delimita a existência dos grupos étnicos. Fredrik Barth defende que o foco da investigação antropológica seja a fronteira étnica que define o grupo e não a substância cultural que ela encerra. Porém, fronteiras étnicas ou limites entre os grupos devem possibilitar que um observador externo aponte as diferenças objetivas. Considerando-se os sinais diacríticos, que são símbolos que contribuem para afirmar as diferenças que os próprios atores sociais consideram significativas, é importante que os elementos que conformam os critérios de pertença a uma identidade básica sejam apresentados como elementos definidores das fronteiras de cada grupo. Isso permite olhar para cada grupo indígena como uma forma de organização social onde interessa menos o traço cultural atribuído do que a própria característica de auto-atribuição e de atribuição por outros (BARTH, 1998, p. 153).

Outra conceituação juridicamente importante refere-se às diferenças entre imemoriabilidade e tradicionalidade da ocupação. Esta última é o que consta efetivamente da Constituição. Benedito Ferreira Marques, ao explicar a distinção entre esses termos, vale-se de conceitos trazidos pelo Estatuto do Índio. No sistema demonstrado por Marques (2011), os territórios indígenas podem ser classificados em três categorias: a) terras tradicionalmente ocupadas; b) terras adquiridas segundo os instrumentos previstos no Código Civil, incluindo a usucapião indígena; c) terras constituídas em reservas. Terras reservadas podem ser oriundas de reservas indígenas, que são áreas destinadas a servir de habitat para um povo (uma aldeia). Um parque indígena possui, além das áreas previstas nas reservas, outras terras que possibilitam a assistência econômica, educacional e sanitária, além de reservas florestais. Caso o Poder Público decida constituir em reserva áreas pertencentes a particulares, somente poderá fazê-lo mediante o instituto da desapropriação, uma vez que não cabe demarcação nesses casos, mas apenas para as terras tradicionalmente ocupadas. A conclusão do autor é que terras reservadas distinguem-se de 
terras ocupadas, "que são aquelas de posse imemorial" (MARQUES, 2011, p. 117).

Visão distinta da categorização feita por Benedito Marques foi expressa por Antônio Armando Albuquerque, que chama a atenção para o fato de que a Convenção 169 também reconhece o direito de propriedade dos povos indígenas sobre as terras por eles tradicionalmente ocupadas, incluindo os direitos sobre os recursos naturais. Terras imemoriais e tradicionalmente ocupadas são conceitos que não se misturam, ainda que possam levar a equívocos nas decisões judiciais que interpretam a Constituição considerando a imemorialidade como o requisito exigido. Por imemorial se afirma de coisas que, de tão antigas, não fazem parte da memória recente. Contudo, terras ocupadas tradicionalmente não o são no sentido de imemoriais, nem a Constituição o exigiu (ALBUQUERQUE, 2008, p. 228). Esse autor ainda destaca que a Constituição protege os direitos à diferenciação étnica para os diferentes grupos indígenas existentes, "uns mais sedentários, outros mais nômades, garantindo o direito às suas terras seja qual for a ordem social (ib., p. 229). Portanto, para garantir a posse da terra às etnias nômades, é necessário afastar o conceito de que somente se possa reconhecer terras que sempre foram ocupadas em toda extensão pelas etnias que as reivindicam.

O que mudou na Constituição de 1988 em relação às cartas anteriores foi uma ampliação da perspectiva de atingimento de direitos pelas minorias. Isto é, em se tratando de direitos fundamentais ou direitos sociais, não pode haver a supremacia do interesse da maioria sobre os direitos de minorias. A ideologia de Estado, antes de 1988, pressupunha que os índios, embora tivessem direito à terra, deveriam se integrar ${ }^{7}$ aos demais grupos étnicos nacionais, brancos, negros, pardos. Embora tal integração aparente ter seu lado positivo ${ }^{8}$, um objetivo subliminar ${ }^{9}$ é que índios "civilizados" vivem na zona urbana e não precisam de terras.

\footnotetext{
${ }^{7}$ Isto está patente no Art. $1^{\circ}$ do Estatuto do Índio, para o qual a Lei que regula a situação jurídica dos índios ou silvícolas e das comunidades indígenas tem, dentre outros, o propósito de "integrá-los, progressiva e harmoniosamente, à comunhão nacional".

8 Algumas minorias podem ser marginalizadas na sociedade em função de sua desigual capacidade de competição. Isso justifica a adoção de políticas afirmativas, que são medidas tomadas com o objetivo de eliminar desigualdades historicamente acumuladas, garantindo a
} 
Ao salientar a importância da manutenção dos laços culturais para as minorias, índios inclusive, a Constituição libertou o direito da perspectiva integracionista prevista no Estatuto do Índio, reforçando a ideia de que não é apenas com direitos sobre terras que se liberta um povo, mas com a valorização de seu sentido de pertencimento e de territorialidade. Isso vem ao encontro do disposto no Decreto no 5.051/1994, que promulgou a Convenção OIT no 169, sobre povos indígenas e tribais, cuja ratificação reforçou entre nós as bases do multiculturalismo ${ }^{10}$ na compreensão da dimensão indígena para a cultura do povo brasileiro ao prescrever o dever do Estado no sentido de reconhecer e proteger os valores e práticas sociais, culturais, religiosos e espirituais próprios dos povos indígenas. Nesse sentido, como parte do processo de reconhecimento passa pela garantia aos índios da posse permanente das terras por eles habitadas e o usufruto exclusivo dos recursos naturais, conforme determinado também na Constituição, deve a Funai exercer seu mister mediante a promoção dos estudos de identificação, delimitação, demarcação, regularização fundiária e registro das terras tradicionalmente ocupadas pelos povos indígenas.

\subsection{Decreto no 1.775/1996 e a demarcação de terras indígenas}

O dispositivo legal do Estatuto do Índio que determinava que as terras indígenas deveriam ser demarcadas foi regulamentado, já na égide da atual Constituição, pelo Decreto no 1775/1996, que dispõe sobre as

igualdade de oportunidades e tratamento, bem como de compensar perdas provocadas pela discriminação decorrente de motivos raciais, étnicos, religiosos, de gênero e outros. Um dos mecanismos de implementar ações afirmativas é por meio de medidas de integração, que contribuam para afastar práticas segregacionistas.

9 Assim se diz de qualquer conduta que não seja suficientemente intensa para que o indivíduo tome consciência dela, mas que, repetida, atua no sentido de alcançar um efeito desejado não explicitado.

10 Will Kymlicka estudou o multiculturalismo em sua proposta para a reivindicação dos direitos das minorias culturais no contexto das sociedades democráticas liberais. Conforme descrito pelo autor, esses grupos "devem ser protegidos contra a discriminação, mas a manutenção e reprodução desses grupos deve ser deixada à livre escolha dos indivíduos e a esfera privada não deve ser ajudada ou prejudicada pelo estado" (KYMLICKA, 2002, p. 50). Além disso, minorias etnoculturais não podem aceitar simplesmente serem integrados em uma das instituições nacionais, devendo atuar para manter e proteger seus próprios interesses associados com as tradições e os laços comunitários. 
etapas do procedimento administrativo de identificação e delimitação para fins de demarcação. De forma complementar, e abrangendo um dos aspectos da gestão territorial, em seu caráter ambiental, foi editado o Decreto no 7.747/2012. Ainda no campo da regulamentação infra legal, a Portaria do Ministério de Justiça no 14/1996 estabeleceu regras sobre a elaboração do RCID, que é o documento que dá as bases técnicas para a decisão de demarcação. Cabe destacar a Portaria da Funai no 116/2012, que estabeleceu diretrizes e critérios a serem observados na concepção e execução das ações de demarcação de territórios indígenas, valorando a participação dos povos indígenas no processo de delimitação para fins de demarcação.

Uma maneira de compreender o processo administrativo para demarcar os territórios indígenas no Brasil é por meio do estudo dos dispositivos do Decreto no 1775 , de 08/01/1996. O procedimento subdivide-se em diversas etapas. A demarcação é apenas o fecho de um processo administrativo conduzido por um GT nomeado pela Funai para fins de elaboração do RCID das áreas reivindicadas. A equipe técnica é composta por um antropólogo, designado pelo órgão central da Funai, e por servidores da Unidade Local, conhecedora da realidade fundiária das áreas a serem vistoriadas. Na forma do Decreto, a Funai deve nomear um grupo técnico especializado, composto preferencialmente por servidores do próprio quadro funcional, coordenado por um antropólogo, com a finalidade de realizar estudos complementares de natureza etno-histórica, sociológica, jurídica, cartográfica, ambiental e o levantamento fundiário necessário à delimitação.

Quanto aos levantamentos fundiários, o Parágrafo $2^{\circ}$ do artigo $2^{\circ}$ do Decreto estabelece que tal levantamento fundiário "será realizado, quando necessário, conjuntamente com o órgão federal ou estadual específico, cujos técnicos serão designados no prazo de vinte dias contados da data do recebimento da solicitação do órgão federal de assistência ao índio".

Vale destacar que, para Paulo de Bessa Antunes, no Decreto $n^{\circ}$ 1775/1996, o contraditório decorre de mandamento constitucional e "tornou-se mais meridiano, mais límpido. Foi expressamente estabelecido 
que todos aqueles que se julgassem prejudicados com o reconhecimento administrativo de territórios indígenas" poderiam apresentar impugnação administrativa para evitar o reconhecimento dos territórios indígenas (ANTUNES, 2012, p. 1109). No entanto, a Funai não atua com a necessária transparência na fase de execução do RCID a partir da leitura que faz do Decreto no $1775 / 1996$ de que o trabalho administrativo, na fase de investigações e levantamentos para fins de elaboração do RCID, não está sujeito ao contraditório, devendo esse existir apenas após a publicação do resumo do RCID. Por se tratarem os estudos para fins de demarcação em deveres técnico-profissionais complexos, que devem ser bem desempenhados pela Funai, surge a obrigação de que a demarcação seja tecnicamente rigorosa, condição para proporcionar maior segurança jurídica no processo administrativo, "gerando maior tranquilidade para a sociedade e para os próprios indígenas" (Ibidem, p. 1110).

Conforme determinação legal, o referido RCID deve cumprir os requisitos técnicos necessários para estabelecer regular processo demarcatório. Para tanto, é necessária a observância dos atributos da clareza e nitidez, devendo explicitar o processo as quatro situações previstas na Constituição, que consubstanciam, em conjunto e sem exclusão, o conceito de "terras tradicionalmente habitadas pelos índios", a saber: (a) as áreas "por eles habitadas em caráter permanente", (b) as áreas "utilizadas para suas atividades produtivas", (c) as áreas "imprescindíveis à preservação dos recursos ambientais necessários ao seu bem estar", e (d) as áreas "necessárias à sua reprodução física e cultural, segundo seus usos, costumes e tradições".

A ocorrência de falhas na atuação administrativa da Funai no processo demarcatório resulta em insegurança jurídica e, em alguns casos, na possibilidade de provocar perturbação da ordem pública quando o processo demarcatório afetar os interesses de grande quantidade de pessoas, quando não for suficientemente clara a caracterização da terra indígena ou não tipificar de modo inequívoco a ocupação tradicional pelos índios. Além disso, o trabalho técnico-antropológico deve demonstrar o marco temporal para fins de caracterização da tradicionalidade da ocupação 
indígena, além dos elementos que definem uma terra como indígena, segundo usos, costumes e tradições dos povos. Com isso, o objetivo desse trabalho deve ser apurar se existe o direito à terra por parte do povo que a ocupa e em que extensão, produzindo trabalho com adequada precisão técnico-científica, condição para legitimar a pretensão à terra, independentemente de qualquer ato constitutivo que beneficie não índios.

Sendo a demarcação de uma terra indígena um ato declaratório, cujo objetivo é precisar a real extensão da posse de modo a assegurar a plena eficácia do dispositivo constitucional, há que se ter o cuidado nas diversas fases dos trabalhos de demarcação de áreas indígenas, para que se possa ter segurança jurídica para todos os envolvidos, o poder estatal, os tutelados e os particulares afetados.

\subsection{Aspectos antropológicos na demarcação dos territórios indígenas}

O Decreto no 1775/1996 estabelece que seja realizado um estudo coordenado por um "antropólogo de qualificação reconhecida", que coordenará os trabalhos do GT que podem resultar na caracterização de terra que, então será declarada "de ocupação tradicional" por Decreto Federal não numerado, possibilitando o reconhecimento do direito originário dos índios sobre uma determinada extensão de terra do território brasileiro.

Portanto, conforme estabelece o próprio manual elaborado pela Funai para orientação dos antropólogos designados para compor os grupos técnicos para os trabalhos de delimitação de áreas indígenas (BRASIL, MINISTÉRIO DA JUSTIÇA, FUNDAÇÃO NACIONAL DO ÍNDIO, 1997), o RCID é a principal peça para a justificativa e fundamentação de uma terra indígena, para efeito de demarcação e regularização oficial desta.

Em face de possíveis questionamentos jurídicos ${ }^{11}$ e administrativos ${ }^{12}$ sobre o trabalho antropológico desenvolvido na fase de delimitação de

\footnotetext{
${ }^{11}$ Pelo Art. 50, inciso XXXV, da CRFB, toda alegação de lesão ou ameaça a direitos líquidos e certos pode ser peticionada pelos interessados (ou legitimados) para fins de apreciação pelo Poder Judiciário.
} 
terras, é necessária uma maior aproximação entre o produto técnico oriundo da pesquisa antropológica e a jurisprudência sobre o assunto.

Quanto aos estudos antropológicos, devem conter a proposta de limites e os estudos complementares necessários à delimitação e posterior demarcação e regularização da terra, sendo tais trabalhos coordenados por antropólogo, profissional esse que deve ter a formação técnica necessária para compreender a forma específica de organização social do grupo indígena que reivindica a terra, devendo os limites propostos contemplar as condições necessárias à preservação do grupo étnico em questão.

Um trabalho antropológico na identificação dos direitos de um povo indígena que reivindica um território não pode prescindir de critérios que auxiliem a compreensão do grupo étnico envolvido. Philippe Poutignat e Jocelyne Streiff-Fénart desenvolveram argumentos que auxiliam no processo de construção da etnicidade. Sua principal problemática é quanto à discussão das diversas teorias para a etnicidade e para isso os autores dividem o seu texto duas partes, sendo que a primeira parte são debates teóricos acerca da conceituação de etnicidade e a segunda parte é a tradução do texto de Fredrik Barth que trata de aplicação e/ou formulação de teorias sobre etnicidade. O objetivo principal é definir parâmetros constituidores da etnicidade, que se refere a um conjunto de atributos ou de traços tais como a língua, a religião, os costumes, o que a aproxima da noção de cultura, ou à ascendência comum presumida dos membros. Apontado o caráter relacional da etnicidade, "a etnicidade não se manifesta nas condições de isolamento, é, ao contrário, a intensificação das interações características do mundo moderno e do universo urbano que torna saliente a identidade étnica" (POUTIGNAT; STREIFF-FÉNART, 1998, p. 124). Ou seja, é por meio das diferenças culturais que a etnicidade se evidencia. Isso quer dizer que, havendo uma comunicação entre diferentes culturas, a identidade étnica se define. Nesse contexto, a partir do estudo

\footnotetext{
12 Conforme o Art. 20, $\S 8^{\circ}$ do Decreto $1775 / 1996$, podem os entes federativos em que se localize a área sob demarcação, bem como demais interessados, manifestar-se apresentando à Funai as razões instruídas com todas as provas pertinentes, tais como títulos dominiais, laudos periciais, pareceres, declarações de testemunhas, fotografias e mapas, para o fim de pleitear indenização ou para demonstrar vícios, totais ou parciais, do relatório de que trata o parágrafo anterior.
} 
antropológico, é possível construir uma proposta de limites fundamentada nas identidades que são reconhecidas.

Cabe ao antropólogo realizar seu trabalho técnico específico e orientar os outros trabalhos necessários a essa fase de identificação. Apesar de ter ascendência sobre o GT, os trabalhos de identificação exigem conhecimentos técnicos específicos que fazem deste um trabalho de equipe. As divergências que possam ocorrer deverão ser argumentadas e discutidas tecnicamente nos relatórios específicos.

\section{Controvérsias no processo demarcatório}

A não observância dos requisitos normativos que orientam o processo demarcatório ou a suposta lesão a interesses de terceiros ocupantes de terras reivindicadas pelos índios tem dado margem a muitas ações contestatórias, inclusive em juízo. Isso requer do procedimento de identificação e delimitação cuidados para evitar lacunas deixadas nos RCID ou que tragam fragilidades em seus próprios termos (RCID com omissões ou contradições) ou que contenham princípios, sistemáticas e contextos políticos distintos.

Do ponto de vista da Administração Pública, que deve procurar evitar a produção de atos que tragam insegurança jurídica, é essencial que o trabalho de identificação explore toda a extensão e limites propostos com dados de pesquisa de acordo com os itens previstos nas normas, o que nem sempre ocorre. Analisam-se as consequências de erros administrativos cometidos na definição de parâmetros técnicos no processo demarcatório de terras indígenas.

2.1 Conflitos com ocupantes não índios em processos de demarcação

A atuação do órgão de proteção dos índios tem sido fortemente questionada por ocupantes não índios das terras em processo de 
demarcação, sob a alegação de ampliação indevida dos limites ocupados tradicionalmente pelas populações indígenas. No caso das demarcações em curso, cujos decretos homologatórios não tenham sido objeto de registro em cartório imobiliário ou na Secretaria do Patrimônio da União (SPU), os interessados poderão manifestar-se contrariamente, o que não raro determina a instauração de conflitos fundiários.

Uma possível atuação com excessos da parte da Funai não representa prejuízo imediato ao erário, pois o que se discute é a existência ou não do direito de ocupante privado de manter a posse ou propriedade ${ }^{13}$, mas significa ameaça a direito de propriedade garantido constitucionalmente.

Para Alcir Gursen de Miranda, quando a Funai produz o RCID que identifica a terra como indígena, deve a autoridade competente ter em mente os requisitos do artigo 231 da Constituição, sabendo-se que "se errar, para mais ou para menos, caberá a correção do ato administrativo ex-offício ou mediante provocação em instância administrativa ou judicial [porque] o erro para mais poderá lesar direito alheio" (MIRANDA, 2006, p. 350).

Afora esse aspecto, um processo demarcatório pode resultar em custos para o Estado em face de uma possível ação de desintrusão na conclusão do processo demarcatório, bem como com o reassentamento de ocupantes não índios. No estado de Mato Grosso ocorreu, no final de 2012, conflito dessa natureza na TI Marãiwatsédé, no nordeste do estado, reconhecida como de propriedade dos índios Xavante. O processo de desintrusão representou grande soma de recursos federais (a Justiça Federal é competente no caso), além de mobilizar um considerável contingente da Força Nacional de Segurança, da Polícia Federal e Polícia Rodoviária Federal. Houve bloqueio da Rodovia BR-070 pelos manifestantes contrários à demarcação. Posseiros da área conhecida como Posto da Mata, onde se concentrou a resistência à desocupação, provocaram grave perturbação na ordem pública no local.

\footnotetext{
13 Há casos em que o título de propriedade foi concedido pelo Estado, nos processos de colonização oficialmente permitida, com registro das terras em cartório.
} 
Segundo declarações dos ocupantes não índios da área Marãiwatsédé, reproduzidas nos meios de comunicação, além da omissão da Funai ao deixar de adotar as medidas administrativas subsequentes à edição do decreto demarcatório, faltou da parte do Instituto Nacional de Colonização e Reforma Agrária (Incra) um plano que estabelecesse um planejamento para a desintrusão e a realocação das famílias de ocupantes não indígenas. Nesse sentido, nos termos no Decreto no 1775/1996, "verificada a presença de ocupantes" não índios na área sob demarcação, o órgão fundiário federal dará prioridade ao respectivo reassentamento, segundo o levantamento efetuado pelo GT, observada a legislação pertinente, nos termos do artigo $4^{\circ}$ do Decreto 1775/1996.

A Portaria no 303 da Advocacia Geral da União, de 16 de julho de 2012, dispôs sobre as salvaguardas institucionais às terras indígenas conforme entendimento fixado pelo STF na Petição 3.388 RR. A referida norma fixou a interpretação das salvaguardas às terras indígenas, a ser uniformemente seguida pelos órgãos jurídicos da Administração Pública Federal direta e indireta, conforme o decidido pelo STF quanto à Terra Indígena Raposa Serra do Sol, em Roraima, e regulamenta dispositivos do Decreto no 1.775/1996, suspendendo o processo de ampliação de territórios indígenas (condicionante XVII) e assegurando a participação dos entes federados no procedimento administrativo de demarcação dos territórios indígenas, encravadas em seus territórios, observada a fase em que se encontrar o procedimento (condicionante XIX). No entanto, em face da reação de setores indigenistas, a vigência da mencionada norma da AGU foi suspensa ${ }^{14}$. Com a decisão do STF no julgamento de embargos ao acórdão que decidiu a Petição 3.388 RR, que entendeu que a decisão somente se aplicava ao caso examinado, as condicionantes não puderam ser generalizadas para outros casos, conforme pretendia a Portaria 303/2012 da AGU. Contudo, embora não tenha pacificado a situação com o julgamento dos embargos, o STF estabeleceu uma jurisprudência que, salvo novos juízos a partir da recomposição da Corte Suprema, pode servir de baliza para outros julgamentos.

14 A Advocacia-Geral da União, por meio da Portaria AGU No 415, de 17 de setembro de 2012, suspendeu a vigência da Portaria AGU no 303/2012. 
Outro conflito potencial decorre do processo de ampliação da TI Enawenê-Nawê, no município de Juína/MT, em que o argumento da população não índia era de que a presença indígena na região pleiteada é recente, de pouco mais de $10 \operatorname{anos}^{15}$. Segundo tais fontes, os índios provêm de país limítrofe com o Brasil, no caso, a Bolívia, que faz divisa com Mato Grosso. Isso indica que a compreensão por parte da população não índia quanto às características nômades de algumas etnias é questão que requer um avanço no campo normativo, uma vez que o sistema legal brasileiro é fortemente influenciado pelo positivismo jurídico, requerendo que normas postas sejam suficientemente detalhadas e prevejam todas as circunstâncias com as quais se defronta a autoridade do Poder Executivo, que não pode agir senão dentro dos limites estabelecidos pela lei.

2.2 Imprecisão técnica na definição dos limites geodésicos propostos nos relatórios de identificação e delimitação

A Portaria do Ministério da Justiça no 14, de 09 de janeiro de 1996, exige que o RCID contenha dados de levantamento fundiário e dos limites propostos para a demarcação. Os dados coletados em campo são apresentados no RCID em item específico, ao final do trabalho, denominado de "conclusão e proposta de limites da área demarcanda". São apresentados os pontos de coordenadas ${ }^{16}$ coletados pelo GT em GPS, que servem para delimitar os vértices ${ }^{17}$ da área proposta.

\footnotetext{
${ }^{15}$ Esse ponto de vista foi apresentado em portal da internet denominado 'Questão Indígena'. Não consta a autoria da matéria. Disponível em http://www.questaoindigena.org/2013/02/proposta-de-ampliacao-de-terra-indigena.html. Acesso em 20 ago. 2013.

16 A apresentação dos dados geográficos é feita segundo o Sistema de Informação Geográficas que considera cada ponto da superfície terrestre segundo sua localização obtida pela interseção de um meridiano com um paralelo. Nesse modelo, os meridianos são círculos máximos cujos planos contêm o eixo de rotação ou eixo dos polos, sendo o meridiano de origem aquele que passa pelo antigo observatório britânico de Greenwich. A oeste de Greenwich, que é o caso do território brasileiro, as medidas decrescem até o limite de $-180^{\circ}$. O outro referencial é a linha do Equador, paralelo imaginário que divide a Terra em dois hemisférios. No hemisfério Sul, onde se situa a maior parte do território brasileiro, partindo do Equador as medidas variam até $-90^{\circ}$.

17 Vértice é todo local onde a linha limítrofe do imóvel muda de direção ou onde exista interseção desta linha com qualquer outra linha limítrofe de imóveis contíguos ou servidões
} 
A utilização das informações georreferenciadas é uma tendência atual para conferir precisão às informações referentes à localização de imóveis rurais. A Lei 10.267 , de 28/08/2001, tornou obrigatória a certificação de imóveis contendo as coordenadas dos vértices definidores dos limites dos imóveis rurais, georreferenciadas ao Sistema Geodésico Brasileiro ${ }^{18}$ e com precisão posicional fixada pelo Incra, tendo por objetivo garantir confiabilidade na geometria descritiva do imóvel rural, de forma a dirimir conflitos decorrentes de sobreposição com imóveis limítrofes. Isso é essencial no caso da delimitação das terras indígenas, uma vez que o objetivo principal é estabelecer os limites físicos do território ocupado pelos povos indígenas, de modo a evitar a ocupação por não índios.

Contudo, uma grande confusão é praticada em boa parte dos relatórios técnicos na definição dos vértices dos limites propostos. O exame de quatorze resumos de RCID de terras indígenas localizadas no estado de Mato Grosso, publicados no Diário Oficial da União ${ }^{19}$, revelou que nenhum fez uma vinculação entre os vértices descritos no RCID a alguma função ambiental, social ou relacionada às necessidades específicas do grupamento indígena considerado. A fundamentação para cada ponto escolhido é essencial para conferir segurança jurídica ao trabalho. Não se pode permitir que a definição dos vértices dependa unicamente do livre convencimento do antropólogo coordenador. Deve haver uma coerência entre as linhas de fronteiras geográficas propostas e as fronteiras identificadas segundo os critérios antropológicos, a partir das narrativas das etnias e nos demais documentos coletados, que ajudem a estabelecer a convicção dos grupos técnicos sobre a localização física dessas fronteiras. Embora a

de passagem (Incra. Norma Técnica para Georreferenciamento de Imóveis Rurais, publicada no Diário Oficial da União em 27/09/2010).

18 Os sistemas de projeção cartográfica necessitam de referenciação ao datum utilizado. Existem sistemas como o SAD-69, o SIRGAS2000, que são oficialmente admitidos no Sistema Geodésico Brasileiro, cujos marcos estão implantados na porção da superfície delimitada pelas fronteiras do país. Outros aparelhos de Global Positioning System utilizam como elipsoide de referência o WGS84, cujos dados apresentam pouca diferença do SIRGAS2000 (AUGUSTO FILHO, 2013, p. 648). Contudo, as diferenças são relevantes entre o SAD-69 e o WGS84. Daí a importância de se informar no Relatório Circunstanciado qual foi o datum empregado nas medições, pois isso a falta da informação pode resultar em grande imprecisão no local que trabalho pretende comunicar. Contudo, a maioria dos relatórios é publicada sem a informação do datum utilizado.

19 Apiaka; Kayabi; Utiariti; Enawenê-Nawê; Bakairi; Umutina; Estação Parecis; Merure; Maraiwatsede Irantxe/Manoki; Enawenê-Nawê; Urubu Branco; Nambikwara; Uiarupuru 
Administração possa decidir discricionariamente em determinadas circunstâncias, os atos administrativos deverão ser motivados, com indicação dos fatos e dos fundamentos jurídicos (Lei 9.784/1999, art. 50). Em outras palavras, se dois vértices definem uma linha, deve haver uma explicação convincente para que tal fronteira observe a linha proposta, que não pode, assim, ser fruto de decisão discricionária do antropólogo coordenador.

Um vértice definido em um local pode incluir ou excluir um rio, uma rodovia construída em tempos recentes, uma construção e diversos outros pontos cuja definição é deixada ao caráter arbitrário da decisão do antropólogo coordenador. Todos ficam expostos a uma decisão equivocada praticada pelo GT, seja a autoridade que tem o dever de homologar ou não o trabalho antropológico, mas que não possui meios de conferir se os limites propostos estão suficientemente explicados, sejam os que terão seus direitos sobre a terra afetados. Até mesmo para a comunidade indígena que espera a ação do Estado no sentido de providenciar a demarcação da terra $^{20}$, e que deve ser ouvida pelo GT no decorrer dos procedimentos administrativos, é crucial que o relatório apresente coerência em seus termos, condição para conferir maior segurança jurídica para o trabalho feito e acelerar o reconhecimento do direito pleiteado.

Em geral as narrativas dos povos indígenas dão subsídios ao trabalho do antropólogo e podem mencionar um cemitério, um rio ou outros acidentes naturais, mas raramente são descritas nos relatórios de maneira suficientemente precisa, em se tratando de áreas de relevo plano, com ou sem cobertura vegetal. Dessa forma, a decisão do GT de situar os vértices do limite neste ou naquele ponto pode ser arbitrária e isso, em parte, decorre da falta de norma administrativa na Funai que preveja critérios objetivos para a decisão.

Existem casos, ainda, em que as áreas delimitadas geograficamente divergem da informação contida na situação histórica descrita. Isso pode

\footnotetext{
${ }^{20}$ A Portaria Funai no 116, de 14 de fevereiro de 2012, prevê que os indígenas poderão participar coletivamente ou de maneira individual nas atividades de demarcação das terras que ocupam e/ou reivindicam.
} 
ser consequência de uma decisão arbitrária, como utilizar uma estrada como limite da área proposta. Uma decisão assim do GT é contraditória com a narrativa histórica da ocupação das terras pelas etnias, se não havia estradas no tempo histórico a que se referem os relatos. Outros casos observados, como a decisão de evitar sobreposição com um assentamento rural $^{21}$ ou manter-se fora dos limites urbanos, configura decisões em que há um choque entre a narrativa antropológica e a propositura de limites da terra demarcada. Às vezes, para que algum direito seja implementado, é preciso que o julgador proponha uma solução salomônica e arbitrária. Há situações, no processo administrativo, em que isso pode ser feito. Mas, a motivação da decisão deve ser claramente explicitada.

\subsection{Judicialização em conflitos sobre terras indígenas}

Segundo acusam os agricultores nos canais de vocalização de seus interesses corporativos, como as Federações de Agricultura, a Funai tem acelerado o processo de demarcação em curso para evitar os efeitos da decisão do STF em relação à demarcação da TI Raposa Serra do Sol. Naquela decisão, os Ministros do STF estabeleceram condicionantes para ampliações de TIs. Conforme Arnaldo Rizzardo, um dos aspectos mais relevantes da decisão do STF é que a data de promulgação da Constituição estabeleceu um marco para definir se há ocupação tradicional pelos índios. Nesse sentido, "deve ser demonstrado que os índios, àquela data, já estavam localizados na área a ser demarcada - marco temporal" (RIZZARDO, 2013, p. 384).

Matéria dessa natureza foi objeto de decisão liminar no Mandado de Segurança MS 28541, impetrado pelos proprietários da Fazenda Iporã, a respeito de ampliação de terra indígena em 184 hectares, sobrepondo-se a área ocupada pela fazenda. A decisão alcança apenas esta área (PROPRIETÁRIOS, 2012). Na liminar, o presidente do STF sentenciou que

\footnotetext{
${ }^{21}$ Delimitação da TI Manoki, em Mato Grosso, cuja área proposta procurou evitar sobreposição com Projeto de Assentamento Tibagi, em Brasnorte.
} 
estavam presentes os pressupostos para a concessão da medida cautelar. Segundo ele, "são plausíveis os argumentos quanto à violação ao devido processo legal, à ampla defesa e ao contraditório". Além disso, documentos atestam que o registro do imóvel é de 1924, data muito anterior, portanto, a 5 de outubro de 1988 (data da promulgação da Constituição), marco fixado pelo STF no caso Raposa Serra do Sol para o reconhecimento, aos índios, dos direitos originários sobre as terras que tradicionalmente ocupam. Nos autos do MS 28541, há documento comprovando a transferência da propriedade do imóvel a particulares e ratificada pelo Incra. Por isso, na liminar o julgador decidiu que "o periculum in mora parece evidente. O decreto homologatório foi publicado no último dia 21 de dezembro de 2009 e, a qualquer momento, poderá a União proceder ao registro no cartório imobiliário, com a consequente transferência definitiva de propriedade".

Outra circunstância considerada na decisão liminar foi a notícia de que a publicação do decreto homologatório gerou a movimentação de lideranças indígenas para, nos próximos dias, perpetrarem atos de ocupação das terras demarcadas. Na inicial, os proprietários alegaram que o Decreto no 1.775/1996 garante a participação dos interessados em todas as fases do processo administrativo e que os impetrantes sequer foram notificados da deflagração do processo demarcatório.

Uma fragilidade do trabalho da Funai alegada pelos impetrantes do Mandado de Segurança MS 28541 é que os índios que estão no local o teriam "invadido" em 2001 e que o estudo antropológico realizado pela Funai seria falho, na medida em que teria se baseado exclusivamente em entrevistas com os índios.

Por fim, sustentam os críticos da atuação da Funai, no caso examinado, que existe prova, na cadeia dominial do imóvel em litígio, de que a área foi transferida pelo estado do Mato Grosso ao domínio privado no ano de 1924, tendo sido ocupada apenas por não índios. Este último argumento é frágil diante de uma jurisprudência consolidada no sentido de que o direito à demarcação de territórios indígenas não pode ser impugnado com base no direito de propriedade. 
O que ocorre, de acordo com Arnaldo Rizzardo, é que o Poder Judiciário é frequentemente convocado a sopesar os direitos à propriedade, que é direito fundamental garantido pela Constituição, com o direito à demarcação de territórios indígenas. A única alternativa processual com possibilidade de sucesso para o não índio é contestar a pretensão demarcatória alegando falhas na elaboração do RCID, de vez que se o juiz da causa se convencer de que a área em litígio for tradicionalmente ocupada pelos índios, não haverá chances de sucesso para a parte litigante (RIZZARDO, 2013, p. 387).

Conforme depoimento do prefeito de Juína dado ao Jornal do Norte de Mato Grosso, "a demarcação que está pedindo a Funai vai pegar quase todo o município de Juína". Segundo estimativa das autoridades municipais de Juína, os índios da etnia Enawenê-Nawê possuem população em torno de mil índios, tendo já titulados um milhão e cem mil hectares ${ }^{22} \mathrm{e}$ reivindicariam, adicionalmente, em torno de outros 300 mil hectares ${ }^{23}$.

No julgamento do Mandado de Segurança (RMS no 29087) um produtor rural questionou a declaração de sua propriedade como sendo de posse imemorial (permanente) dos índios da etnia Guarani Kaiowá, integrando a TI Guyraroká, no Mato Grosso do Sul. Em Seção da 2a Turma do STF, o ministro Gilmar Mendes apresentou seu voto-vista, por meio do qual divergiu do relator do processo, ministro Ricardo Lewandowski, que votou no sentido de negar provimento ao recurso ${ }^{24}$. O recorrente busca reverter decisão do Superior Tribunal de Justiça (STJ) que negou mandado de segurança lá impetrado. Em seu voto, deu provimento ao recurso para declarar a nulidade de ato do ministro da Justiça, consubstanciado na

22 A informação dada pelo prefeito de Juína está imprecisa. A TI Enawenê-Nawê, cuja demarcação foi homologada por meio de Decreto em 02/10/1996, abrange parte dos municípios de Sapezal, Comodoro e de Juína, ocupando área total de 742.088,6783 hectares. Mas, de fato, há um processo de ampliação da área demarcada em curso na Funai. ${ }^{23}$ Quanto ao processo em curso em Juína, o prefeito municipal, em declarações à imprensa, afirmou que a demarcação pretendida pela Funai abrangerá $83 \%$ da extensão da cidade. Disponível em http://www.jnmt.com.br/noticias_ver.php?id=4471. Acesso em 31 dez. 2012.

${ }^{24}$ Em outros termos, a posição juridica do ministro Gilmar Mendes, contrária à do ministro Lewandowski, é no sentido de conhecer (acatar) o recurso, permitindo que seja concedido o mandado de segurança proposto pelo proprietário de terras demarcadas, que alega falhas da Funai na instrucão do processo administrative. O julgamento depende do voto de outros ministros do STF, mas a divergência foi citada para exemplificar o tipo de controvérsias jurídicas a que está sujeita a questão. 
Portaria 3.219, de 7 de outubro de 2009. Segundo o ministro Gilmar Mendes, o próprio laudo da Funai aponta que os índios não tinham posse da terra na data da promulgação da Constituição (5 de outubro de 1988) e que viveram na região há mais de 70 anos. O ministro entende que, embora a decisão do STF na Petição (PET) 3388, que julgou a demarcação da TI Raposa Serra do Sol, em Roraima, não tenha efeitos vinculantes, é necessário que a jurisprudência das instâncias ordinárias e do STF se adapte a esse julgado, no qual a Corte estabeleceu uma série de fundamentos e salvaguardas institucionais relativos à demarcação de terras indígenas, como o marco temporal da ocupação e a necessidade de o processo envolver estado e municípios afetados, entre outros. De acordo com o ministro, se ainda assim a União entender que uma área deve integrar determinada terra indígena, deve desapropriá-la e não invocar historicamente uma posse indígena imemorial para resolver a questão no âmbito de um processo demarcatório, que é excepcional e que tem pressupostos (Voto Ministro Gilmar Mendes, RMS n 29087).

Os trabalhos de identificação constituem a primeira etapa do processo administrativo de demarcação dos territórios indígenas, cujos resultados servirão de base a todas as etapas subsequentes. Os estudos antropológicos e complementares realizados nessa fase deverão caracterizar e fundamentar a terra como tradicionalmente ocupada pelos índios conforme os preceitos constitucionais e apresentar elementos visando à posterior demarcação e regularização da terra.

\section{Considerações finais}

A ocupação de territórios indígenas no Brasil foi um processo histórico e nem sempre pacífico, mas que permitiu a consolidação de direitos dos não índios sobre vastas porções do território nacional. O resgate dessas terras pelos indígenas não haveria de ser isento de conflitos, na medida em que significa a desconstituição de direitos das partes contrárias aos interesses dos povos indígenas. A falta de soluções permanentes gera insatisfação 
tanto por parte dos não índios, cujos títulos de domínio ou posse possam ser desconstituídos ao final do processo demarcatório, quanto dos próprios índios, pela lentidão burocratizante do processo administrativo, sujeito a entraves de ordem política, técnica ou jurídica.

Sempre que as dificuldades no reconhecimento dos direitos fundiários indígenas se devam a falhas ou omissões nos procedimentos administrativos desenvolvidos para o reconhecimento dos limites dessas terras, disso pode resultar contestação administrativa ou judicial. Portanto, se existe a convicção por parte da Funai, fundada nas evidências dos levantamentos etnográficos, quanto à procedência da reivindicação à demarcação ou ampliação de terras demarcadas feita pelos índios, é essencial que haja qualidade e rigor na elaboração dos trabalhos pelo GT nomeado a partir da instauração do processo administrativo. Quando se trata de áreas onde existam ocupações por parte de não indígenas, é previsível que haja discussão dos critérios antropológicos, fundiários e técnicos que orientaram os resultados do trabalhos conduzidos pelo GT.

Para minimizar as contestações administrativas ou jurídicas ao trabalho antropológico, que possam causar uma demora injustificada no reconhecimento dos direitos indígenas sobre as terras cuja demarcação reivindicam, o laudo antropológico e as demais peças que resultam no RCID das terras indígenas devem ser produzidos em bases etnográficas suficientemente detalhadas.

A demarcação de territórios indígenas, sendo procedimento administrativo que deve ser conduzido com a melhor técnica antropológica possível, seria um grande passo para o reconhecimento dos direitos dos povos indígenas. Mas, quando feito de forma inadequada, resulta em estudos que não têm capacidade técnica de deixar irrefutáveis as conclusões a que chega, abre caminho para a insatisfação social. Havendo reconhecimento dos direitos de povos indígenas sobre as terras ocupadas por não índios, após a edição do decreto de homologação, aí sim, cumpre aos órgãos de governo atuar de forma rápida no sentido de concluir o processo de demarcação dos territórios indígenas homologadas, evitando 
que a demora no processo de desintrusão resulte em prejuízos para os que ocupam de boa-fé as áreas demarcadas.

Em síntese, terras indígenas, sendo bens públicos inalienáveis e indisponíveis, devem ser delimitadas de forma a assegurar às populações indígenas a sua delimitação. O processo de demarcação não deve ser tão rápido que possa produzir estudos incapazes de suportar a oposição dos grupos legitimados para o contraditório, nem deve ser tão lento a ponto de afetar os direitos dos povos indígenas, ao mesmo tempo em que o órgão de assistência aos índios assiste passivamente à exploração dos territórios indígenas por não índios.

Ainda que o Poder Judiciário tenha reconhecido em suas decisões que o prazo de cinco anos constitucionalmente estabelecido para a conclusão dos processos demarcatórios não implica em decadência do direito dos índios ao usufruto das terras que tradicionalmente ocupam, há um entendimento jurídico de que o processo administrativo de reconhecimento desses direitos deve observar um limite razoável em sua duração. Portanto, se o processo de demarcação não for adequadamente conduzido e em prazo razoável, há riscos de prejuízo a direitos, tanto dos índios que não teriam acesso às terras enquanto inconclusos os procedimentos, quanto por parte dos não-índios que não estejam ocupando áreas indígenas que, por não saberem se estão ou não dentro dos limites fixados no processo de delimitação, deixam de utilizá-las de modo sustentável enquanto padecem da insegurança jurídica que afeta a todos.

A $1^{\text {a }}$ Conferência Nacional de Política Indigenista, realizada em Brasília, Distrito Federal, no período de 17 a 20 de novembro de 2015, teve por objetivos: avaliar a ação indigenista do Estado brasileiro; reafirmar as garantias reconhecidas aos povos indígenas no País; e propor diretrizes para a construção e a consolidação da política nacional indigenista.

Tendo a Conferência o propósito de servir de instância de participação social diferenciada, visando à promoção de um espaço de diálogo e atuação conjunta entre a administração pública e os mais de 300 povos indígenas do Brasil, permitiu avaliar a ação indigenista do estado 
brasileiro, tendo as representações indígenas reforçado a luta pelos seus direitos constitucionais. A Conferência possibilitou que um total de 868 propostas fossem consolidadas, das quais 216 foram caracterizadas como urgentes. Dentre as reivindicações de caráter urgente, está a que pede a aceleração dos processos de demarcação e a homologação das áreas demarcadas.

Nesse sentido, é papel do meio acadêmico, especialmente dos antropólogos e dos geógrafos, contribuírem em novas reflexões que sirvam de marco teórico na busca de soluções para as dificuldades apontadas, de modo a construir uma nova relação do Estado brasileiro com os povos indígenas no Brasil sob o paradigma da Constituição de 1988.

\section{Referências bibliográficas}

ALBUQUERQUE, Antônio Armando Ulian do Lago. 2008. Multiculturalismo e direito à autodeterminação dos povos indígenas. Porto Alegre: Sérgio Antônio Fabris.

ANTUNES, Paulo de Bessa. 2012. Direito ambiental. 14. ed. São Paulo: Atlas.

ARAÚJO, Ana Valéria. 2004. "Terras indígenas no Brasil: retrospectiva, avanços e desafios do processo de reconhecimento". In: RICARDO, Fany (org.). Terras Indígenas e Unidades de Conservação da natureza: o desafio das sobreposições. São Paulo: ISA.

AUGUSTO FILHO, Oswaldo. 2013. "Sistemas de informações geográficas aplicados à engenharia ambiental". In: CALIJURI, Maria do Carmo; CUNHA, Fernandes (coord.). Engenharia Ambiental: conceitos, tecnologia e gestão. Rio de Janeiro: Elsevier.

BARTH, Fredrik. 1998. "Grupos étnicos e suas fronteiras". In: POUTIGNAT, Philippe; STREIFF-FENART, Jocelyne. (orgs.). Teorias da Identidade. São Paulo: UNESP.

BRASIL. Advocacia Geral da União. Portaria no 303, de 16 de julho de 2012. Dispõe sobre as salvaguardas institucionais às terras indígenas conforme entendimento fixado pelo Supremo Tribunal Federal na Petição $3.388 \quad$ RR. Disponível em: http://www.agu.gov.br/sistemas/site/PaginasInternas/NormasInternas LAtoDetalhado.aspx?idAto =596939. Acesso em: $31 \mathrm{dez} .2012$.

. Ministério da Justiça. Fundação Nacional do Índio. Procedimentos para identificação de territórios indígenas: Manual do Antropólogo-Coordenador. $1^{\text {a }}$ versão. 10/10/1997. Disponível em: 
$<$ http://www.Funai.gov.br/quem/legislacao/pdf/Manual_Antropologo.p df $>$

Acesso em: 31 dez. 2012.

- Ministério da Justiça. Portaria no 14, de 9 de janeiro de 1996. Estabelece regras sobre a elaboração do Relatório circunstanciado de identificação e delimitação de territórios indígenas a que se refere o Decreto no 1.775, de 08 de janeiro de 1996.

- Poder Judiciário Federal. Superior Tribunal Federal. Decisão. Medida cautelar no mandado de segurança 24.566-2. Brasília, 16 março 2003.

Presidência da República. Decreto no 1.775, de 8 de janeiro de 1996. Dispõe sobre o procedimento administrativo de demarcação dos territórios indígenas e dá outras providências. Disponível em: <http://www.planalto.gov.br/ccivil_03/decreto/D1775.htm>.

Acesso em: $31 \mathrm{dez} .2012$.

IRIGARAY, Carlos Teodoro José Hugueney. 2007. "Do estado de guerra ao estado de bem-estar ambiental: contribuição indígena ao contrato de armistício". In: Revista de Estudos Sócio-Jurídico-Ambientais Amazônia Legal, v. 2, p. 67-101.

KYMLICKA, Will. 2002. Politics in the vernacular: nationalism, multiculturalism and citizenship. New York: Oxford University Press.

MARQUES, Benedito Ferreira. 2011. Direito agrário brasileiro. 9. Ed. São Paulo: Atlas.

MIRANDA, Alcir G. 2006. "Áreas indígenas". In: BARROSO, Lucas de Abreu; MIRANDA, Alcir Gursen; SOARES, Mário Lúcio Quintão (orgs.). 0 direito agrário na Constituição. Rio de Janeiro: Forense.

POUTIGNAT, Philippe; STREIFF-FENART, Jocelyne. (orgs.). 1998. Teorias da Identidade. São Paulo, UNESP.

PROPRIETÁRIOS de fazenda na Terra Indígena Arroio-Korá obtêm liminar suspendendo demarcação. In: STF Informa. Brasília, 28 dez. 2009. Disponível em: $<$ http://www.stf.jus.br/portal/cms/verNoticiaDetalhe.asp?idConteudo= 118284>. Acesso em: 20 ago. 2013.

RIZZARDO, Arnaldo. 2013. Curso de direito agrário. São Paulo: Editora Revista dos Tribunais.

ROMERO, Ellen Cristina Oenning. 2012. Os direitos ambientais dos povos indígenas. Dissertação (Mestrado em Direito Agroambiental). Cuiabá, Universidade Federal de Mato Grosso.

SAUER, Sérgio; ALMEIDA, Wellington (orgs). 2011. Terras e territórios na Amazônia: demandas, desafios e perspectivas. Brasília: Editora UnB. 